reeponsible for that work, whether it, was workman, master, or surveyor? When a few unfaitliful workmen and masters have been brought to book, we may perhaps have some improvement, but not till then.

I am, Sir, yours, \&c.,

Holloway-road, Feb. 26th, $1883 . \quad$ W. HENRY KesteveN.

\section{SANITARY CONDITION OF CALCUTTA.}

\section{To the Editor of TIIE LANCET.}

SIR,-The enclosed letter was written, at the request of Dr. Mouat, on the state of the sewers and drains at Calcutta, as detailed in THE LANCET of the 24th inst. If you wish to use the letter it is at your service.

I am, Sir, yours truly,

R. Rawlinson.

"Dear DR. Mouat,-I have looked over the remarks in the Overland Mail (Calcutta) of January 9th, 1883, as to the condition of the main sewers and drains in that city. It appears that certain outlet sewers are large, and that tributary sewers and drains contain sediment, and are offensive. There are also statements that sewage sediment is allowed to accumulate both in the large main sewers and in the tributary sewers and house-drains, consequent on absence of flushing, disease in excess, especially cholera, being attributed to the stenches from the sewers and drains. The large main sewers connect with the tidal river. There are about thirty-four miles of tributary sewers, and it is said about fourteen million gallons of water per day pass out of the sewers. It is difficult to advise as to works in India other than on general principles. The following remarks and suggestions must therefore be taken for what they may be worth-namely, as the opinions of one who has had a wide experience, and who also has paid much attention to the subject. As a rule surface water in a tropical climate ought not to be carried away through sewers, as these should be proportioned to the volume of sewage. Natural watercourses may be improved, but should not be converted into sewers. Sewers formed in a flat district, and porous subsoil, should be of the best material; the bottom of the trench should be made watertight to prevent leakage of the fluids of sewage. The sewers and drains, in construction, should be absolutely true in line and in gradient, and should also be absolutely watertight, as, if not, the fluids will escape at the joints, leaving sediment to ferment and putrefy. All sewers and drains should be regularly flushed at short and regular intervals, as the ordinary flow of sewage is not, in all cases in flat sewers sufficient in volume to remove the sediment. Sewers and drains may be flushed each day, from an automatic flushing chamber, with a comparatively small volume of water, as under :-

\section{Diameters of Sewers and Drains.}

\begin{tabular}{|c|c|c|c|c|c|c|c|c|c|}
\hline & & & & & aeters. & & & Gall & $\begin{array}{l}\text { ns for one } \\
\text { flush. }\end{array}$ \\
\hline Pipes & & $\ldots$ & $\ldots$ & & ches. & $\ldots$ & $\cdots$ & $\cdots$ & \\
\hline ", & .. & $\ldots$ & $\ldots$ & 9 & , & $\ldots$ & $\ldots$ & $\ldots$ & 80 \\
\hline & $\ldots$ & $\ldots$ & $\ldots$ & 12 & , & $\cdots$ & $\ldots$ & $\ldots$ & 140 \\
\hline 9 & $\ldots$ & $\ldots$ & $\cdots$ & 18 & , & $\cdots$ & $\ldots$ & $\ldots$ & 320 \\
\hline & $\ldots$ & $\ldots$ & $\ldots$ & 24 & ,, & $\ldots$ & $\ldots$ & $\ldots$ & 570 \\
\hline
\end{tabular}

"The above volumes of water may be liberated through the drains and sewers in from three to five minutes. I'o remove old deposits the flushing should be repeated as fast as the flushing tanks can be filled until the drain or sewer has been cleared. If the drains and sewers leak into the subsoil, flushing may, in some cases, cause damage by washing away the sandy subsoil. I know of no remedy but repairs at such points with Portland cement. Sewers and drains in a flat district require unceasing attention in any climate, but under the climate of Calcutta unceasing special attention will always be necessary. Sewers and drains must have full means for ventilation that any gases of decomposing refuse may be dispersed and diluted in the open air. Stenches are offensive in the open air, but they do not kill as when admitted within inhabited houses. If sewer and drain flushing has been neglected in Calcutta, greater attention to this necessary process will tend to reduce the nuisance cansed by the unflushed and foul drains and sewers. "I am, Sir, yours truly,

"RobekT Rawlinson, C.B.

" Chief Engineer Inspector, Local Government Board, "Member of the Armay Sanitary Commission.

"London, Feb. 12th, 1893."
ON PERSONAL PRECAUTIONS THAT MAY BE ADOPTED BY MEDICAL MEN WHILST ATTENDING CASES OF INFEOTIOUS DISEASE.

\section{To the Editor of THE LANCET.}

Sir, - We have had in this district during the last year no less than five medical men and a nuisance inspector down with typhus fever, caught in the discharge of their dangerous duties. Of these, two medical men and the inspector succumbed to the disease. As I hold an appointment which brings me daily in contact with the more dangerous infectious diseases, I have given considerable attention to selfprotection from fever poison, and I think the time has now arrived when medical men should take every precaution likely to prevent their becoming infected. I would suggest that the following precautions be taken when visiting every case of dangerous infectious disease :-

1. Always bave the window open before entering the patient's room or ward. 2. Never stand between the patient and the fire, but always between him and the open window. 3. If possible change your coat before entering the room. 4. Do not go in for any unnecessary auscultation or other physical examination. 5. Stay as short a time as possible in the room. 6. Never, while in the room, swallow any saliva. 7. After leaving the sick room wash the hands with water containing an antiseptic. 8. Rinse out the mouth with diluted "toilet Sanitas" or Condy's fluid, also gargle the throat with it and bathe the eyes, mouth, and nostrils. 9. Expectorate and blow the nose immediately on leaving the sick room. 10. Keep up the general health by good food, exercise, and temperance. 11. In addition to the above recommendations, which are all pretty generally known, I would suggest another, which is, in my opinion, the most important of all. This is to filter all the air you breathe while in the sick room or ward through an antiseptic medium. My method is to use a McKenzie's inhaler over the nose and mouth. I carefully soak the sponge in a strong solution of carbolic acid before entering the sick room. It is so made that all the air breathed must necessarily come through this sponge, and the expired air is emitted, by a valve action, at another place. I have worn this not only in the Fever Hospital wards, but in many of the typhus dens in this borough. It is to this method that I attribute the fact that although I have attended between 200 and 300 cases of typhus during the last twelve months, and seen many more, I have hitherto escaped infection myself. The only objection (which is not of much importance in a hospital) is the unsightly appearance one has with the inhaler in situ. This objection is, however, very slight one when weighed against the greatly increased safety one not only feels, but I believe actually possesses. I am not aware of this method having been mentioned previously, and this fact, and my desire to prevent a repetition of the late disastrous fatalities, must be my apology for bringing it before the profession.

I remain, Sir, yours truly

Charles Green, M.B., M.R.C.S.

Medical Officer of Health, Gateshead Borough, and Mredical March 1st, 1883. Officer of the Borough Fever Hospital.

\section{FERTILITY OF WOMEN IN THE EAST-END OF LONDON.}

To the Editor of THE LANCET.

SrR,-In connexion with Dr. Matthews Duncan's Lectures, now being published in THE LANCET, the following few particulars may be interesting :-

From 100 consecutive family histories, obtained from mothers leaving their children as patients in the East London Hospital, the following facts were elicited :-I found 100 mothers had borne 533 living children, had had 113 miscarriages, and of these children 176 had died. Of course, the numbers are too few for statistical purposes, and, more. over, the age of the mothers is not stated; but most of them were probably considerably past the middle of the childbearing period. As far as these figures go, they seem to indicate that Ansell's and Farr's averages are too low and the average of the Statistical Society too high as applied to the East-end. Of these 100 mothere, eight had 10 or more children. One mother (child admitted with hysteria) had 15 children, 1 miscarriage, and 8 had died. Another (child phthisical) had 14 children, 4 miscarriages, and 4 had died. 